\title{
Acute Intussusception of the Adult in Burkina Faso, a Tropical Area: Our Experience about 30 Cases
}

\author{
Zida Maurice ${ }^{1}$, Ouangré Edgar¹, Ouedraogo Souleymane², Doamba Rodrigue1, \\ Kafando Roch Justin ${ }^{1}$, Zan Abdoulaye1, Traoré Si Simon ${ }^{1}$ \\ ${ }^{1}$ Department of Visceral Surgery, Teaching Hospital Yalgado Ouedraogo, Ouagadougou, Burkina Faso \\ ${ }^{2}$ Department of General Surgery, Teaching Hospital of Ouahigouya, Ouahigouya, Burkina Faso \\ Email: zimaur@yahoo.fr
}

How to cite this paper: Maurice, Z., Edgar, O., Souleymane, O., Rodrigue, D., Justin, K.R., Abdoulaye, Z. and Simon, T.S. (2018) Acute Intussusception of the Adult in Burkina Faso, a Tropical Area: Our Experience about 30 Cases. Surgical Science, 9, 189-196.

https://doi.org/10.4236/ss.2018.96022

Received: May 2, 2018

Accepted: June 12, 2018

Published: June 15, 2018

Copyright $\odot 2018$ by authors and Scientific Research Publishing Inc. This work is licensed under the Creative Commons Attribution International License (CC BY 4.0).

http://creativecommons.org/licenses/by/4.0/

\begin{abstract}
Objective: To describe the etiological, clinical and therapeutic aspects of adults' intussusception at Yalgado Ouedraogo University Hospital in Ouagadougou (CHU-YO), Burkina Faso. Patients and method: This descriptive cross-sectional study was conducted between May 2011 and April 2016 at CHU-YO. All patients with 16 years of age and older operated on for intussusception were included. Results: Thirty patients were identified, 15 men and as many women. Their average age was 37.3 years. A higher frequency was noted between 30 and 39 years. The installation of the symptomatology was insidious in 22 cases and brutal in 8 cases. The reasons for consultation were abdominal pain (30 cases), vomiting (19 cases), intestinal transit stop (18 cases) and rectorrhagia (9 cases). Physical examination noted an abdominal mass in 11 cases and a localized abdominal tenderness in 7 cases. An intussusception coil was identified on ultrasound in 9 cases. All patients underwent surgery under general anesthesia and the approach was laparotomy. Intraoperatively, the intussusception was ileocolic in 15 cases; a right hemi-colectomy was performed. It was colo-colic intussusception in 10 cases and the treatment thus consisted of a left hemi-colectomy. In other 5 cases, intussusception was ileal, requiring ileal resection. The average hospital stay was 11.7 days. Pathologically, the examination was normal in 2 cases. A colic tumor was found in 14 cases and an ileum tumor in 6 cases. In the other 8 cases, it was an inflammatory aspect of the intestine. Conclusion: In tropical Burkina Faso, adult intussusception often occurs on an intestinal tumor. The symptomatology is atypical.
\end{abstract}

\section{Keywords}

Acute Intestinal Intussusception, Adult, Intestinal Tumor, Burkina Faso 


\section{Introduction}

Acute intussusception is a serious condition that can occur at any age. However, acute intussusception of the adult differs from that of the child in its etiological aspects, in its clinical presentation and in its therapeutic modalities [1]. In children, acute intussusception is common and occurs 9 times out of 10 without underlying intestinal pathology; it is so called idiopathic [1]. In adults, acute intussusception is rather rare and accounts for only $5 \%$ to $10 \%$ of all intussusception reported cases [1]. It occurs around age 50, with no clear predominance of sex [2]. It is very often secondary to an underlying intestinal pathological process [1] [3]. The classic triad made by abdominal pain, rectorrhagia and abdominal mass, very often suggestive of the diagnosis in children, is absent in adults and the diagnosis is usually performed intraoperatively [1] [2]. The management of adult intussusception is multidisciplinary. Surgery remains however largely indicated for the restoration of the intestinal transit and for the possible ablation of a tumor. Mortality remains highly variable, between 8 and 50\% depending on the nature of the underlying intestinal pathology [4] [5]. In this study, we present the experience of a sub-Saharan African tropical country on adult acute intussusception. We discuss etiological and prognostic particularities. This study will allow us to specify the etiological specificities of adult's acute intussusception in tropical Africa.

\section{Patients and Method}

The purpose of this study was to describe the etiological, clinical and therapeutic aspects of adult acute intussusception at the visceral surgery department of Yalgado Ouedraogo University Hospital Center, in Ouagadougou. This hospital is the largest hospital in Burkina. CT scanning, laparoscopy and pathological examination in extemporaneous are however not available in emergency. We conducted a descriptive cross-sectional study that covered the period from May 1, 2011 to April 30, 2016. This study involved all patients aged 16 and over, operated for intussusception during this period in the department of visceral surgery of Yalgado Ouedraogo University Hospital Center. The diagnosis of intussusception was evoked on clinical examination, supported by ultrasonography but confirmed intraoperatively. Follow-up of the patients was done during the patient's hospitalization and during the surgeon's consultations. Data collection was retrospective. For each patient included, Parameters such as age, sex, clinical signs, therapeutic modalities, and evolutionary aspects were collected from clinical records. This data was analyzed on a computer using the EPI INFO software. A threshold of 5\% was considered significant for the comparison of the data.

\section{Results}

\subsection{Epidemiological Aspects}

In total, 30 patients were included. Their ages ranged between 16 and 65 years 
with an average of 37.3 years. There was no predominance of sex. Table 1 presents the sociodemographic data of the patients.

\subsection{Clinical Aspects}

The average consultation time was 6.7 days. The installation of the symptomatology was brutal in 22 cases and progressive in 08 cases. The classic triad of AII, abdominal pain vomiting, rectorrhagia, was found in one case. Table 2 summarizes the clinical aspects.

Abdominal ultrasound was performed in all patients. It allowed to visualize the intussusception roll and to specify the type of intussusception in 9 cases. An intestinal tumor was found in 5 cases. The abdominal plain radiography was performed in 11 patients. It found water-level in 9 cases, a diffuse greyness in 1 case.

\subsection{Therapeutic Aspects}

All patients underwent preoperative resuscitation with nasogastric tube, urinary catheter, peripheral venous approach and correction of hydro electrolytic disorders. Blood transfusion was performed in 2 patients. Antibiotic therapy with ceftriaxone was performed at anesthesia induction in all patients and continued for 2 days. General anesthesia was performed. The patients were then operated on by median laparotomy. The peritoneal fluid at the opening of the abdominal cavity was hematic in 19 cases and serous in 11 cases. Exploration revealed ileo-caecalic intussusception in 15 cases, ileal intussusception in 10 patients, left colonic intussusception in 5 cases. Intestine was viable in 27 cases and necrotic in 3 cases. Macroscopically, underlying intestinal pathologies were noted in 20

Table 1. Socio-demographic data of patients.

\begin{tabular}{ccc}
\hline Parameters & Number & Percentage (\%) \\
\hline Age (years) & 2 & 6.7 \\
$16-19$ & 9 & 3.0 \\
$20-29$ & 7 & 23.3 \\
$30-39$ & 4 & 13.3 \\
$40-49$ & 6 & 2.0 \\
$50-59$ & 2 & 6.7 \\
$60-65$ & & \\
Sex & 15 & 50 \\
Male & 15 & 50 \\
Female & & \\
Profession & 13 & 43.4 \\
Housewife & 9 & 30.0 \\
Farmer & 7 & 23.3 \\
Civil servant & 1 & 3.3 \\
Pupil & & 26.7 \\
Area of residence & & 73.3 \\
Urban area & &
\end{tabular}


Table 2. Clinical aspects.

\begin{tabular}{|c|c|c|}
\hline Parameters & Number & Frequencies (\%) \\
\hline \multicolumn{3}{|l|}{ Symptoms at admission } \\
\hline Abdominal pain & 30 & 100.0 \\
\hline Vomiting & 19 & 63.3 \\
\hline Stopping of materials and gases & 18 & 60.0 \\
\hline Rectorrhagia & 9 & 30.0 \\
\hline Diarrhea & 1 & 3.3 \\
\hline \multicolumn{3}{|l|}{ General condition } \\
\hline Altered & 8 & 26.7 \\
\hline Preserved & 22 & 73.3 \\
\hline \multicolumn{3}{|l|}{ State of hydration } \\
\hline Dehydrated & 6 & 20 \\
\hline Non dehydrated & 24 & 80 \\
\hline \multicolumn{3}{|l|}{ Physical signs } \\
\hline Abdominal meteorism & 12 & 40.0 \\
\hline Abdominal defence & 7 & 23.3 \\
\hline Abdominal mass & 11 & 36.7 \\
\hline Rectal mass & 3 & 10.0 \\
\hline \multicolumn{3}{|l|}{ Blood count } \\
\hline Hemoglobin level $<10 \mathrm{~g} / \mathrm{dl}$ & 4 & 13.3 \\
\hline Hemoglobin level $\geq 10 \mathrm{~g} / \mathrm{dl}$ & 26 & 86.7 \\
\hline White blood cells $<10000 / \mathrm{mm}^{3}$ & 7 & 23.3 \\
\hline White blood cells $\geq 10000 / \mathrm{mm}^{3}$ & 23 & 76.7 \\
\hline \multicolumn{3}{|l|}{ Blood Sugar } \\
\hline$<6 \mathrm{mmol} / \mathrm{l}$ & 19 & 63.4 \\
\hline$\geq 6 \mathrm{mmol} / \mathrm{l}$ & 11 & 36.6 \\
\hline \multicolumn{3}{|l|}{ Creatinine } \\
\hline$<120 \mu \mathrm{mol} / \mathrm{l}$ & 7 & 23.3 \\
\hline$\geq 120 \mu \mathrm{mol} / \mathrm{l}$ & 23 & 76.7 \\
\hline
\end{tabular}

patients. There were 11 cases of right colon tumor, 6 cases of ileum tumor, 2 cases of left colon tumor. In addition, mesenteric lymphadenopathies were noted in 6 patients. Desinvagination was possible in 2 patients. The actions performed depended on the type of intussusception. In the case of ileocecal or colo-colic intussusception, a right hemicolectomy was performed. This indication was asked in 15 patients. In case of intussusception on the left colon, a left hemicolectomy with immediate restoration of digestive continuity was performed. Five patients benefited from a left hemi-colectomy. In case of ileal intussusception, an ileal resection was performed, with immediate restoration of continuity. Ten patients were treated according to this modality.

\subsection{Evolutionary Aspects}

The postoperative course was simple in 27 patients. Postoperative peritonitis by discontinuation of intestinal suture was noted in 1 patient and parietal suppuration in 2 other patients. Postoperative peritonitis was resumed and an ileostomy was performed, with restoration of digestive continuity after 4 weeks. Parietal suppurations have been successfully treated with daily dressings. The average hospital stay was 11.7 days. Anatomo-pathological examination of the operative 
specimen was performed in all patients. Table 3 summarizes the results of the anatomo-pathological examination.

\section{Discussion}

Adult Intussusception is a rare condition [6]. It accounts for $5 \%$ to $10 \%$ of acute intussusception and 1\% of bowel obstruction causes in adults [6] [7]. However, its frequency seems higher in Africa, particularly in the tropics, than in the West [8]. The relatively higher frequency in tropical countries could be explained by the high prevalence of certain specific intestinal pathologies such as major salmonellosis, intestinal virosis and chronic parasitosis. These digestive disorders are responsible for mesenteric lymphoid hypertrophies, which can promote intussusception in both adults and children [8].

The average age of patients in our study was 37.3 years. Our patients were relatively young, compared to patients in European series. Indeed, the average age is around 50 in Europe [1] [9]. The age difference could be explained by the variation of adult intussusception etiologies from one region to another. Adult intussusception often appears on an intestinal pathological process that can be benign or malignant. In our context, histological examination revealed 3 benign lesions on 10 ileal pieces examined. In the small intestine, the lesion underlying intussusception is often benign [6] [10] [11]. It is most often inflammatory polyps that are rare on the ileum, but also ileitis. This ileitis is common in tropical environments and occurs during certain viral conditions. The malignant ileal tumors frequently implicated in adult intussusception are adenocarcinoma, malignant hemangioma, and lymphoma [7] [12] [13]. In colonic intussusception, the pathological examination noted an underlying malignant lesion in 11 out of 19 cases. It is generally accepted that colonic intussusception often appear on a pre-existing malignant lesion [14].

In all the cases of our series, the diagnosis was made at the laparotomy, indicated in front of an acute or subacute intestinal obstruction. The clinical presentation of adult intussusception differs from that of the child. The classic triad of pain, abdominal mass and rectorrhagia is present in only about $10 \%$ of cases [14]. In fact, the clinical picture of adult intussusception depends on the

Table 3. Results of the anatomo-pathological examination of the operative parts.

\begin{tabular}{cccc}
\hline Type of invagination & Examined part & Histological aspects & Total number \\
\hline \multirow{2}{*}{ Ileo-caecalic intussusception } & Right colon & Normal & 1 \\
& & Colitis & 2 \\
Ileal intussusception & Ileum & Adenocarcinoma & 3 \\
& & Normal & 1 \\
Colonic intussusception & Leftcolon & Ileitis & 3 \\
& & Adenocarcinoma & 3 \\
\hline
\end{tabular}


underlying pathology, the mode of presentation, and the intestinal segment [14]. Adult intussusception can be acute, subacute or chronic [14]. The most commonly reported symptom is abdominal pain [7]. Despite advances in medical imaging, preoperative diagnosis is only performed in about $45 \%$ of cases without CT [3] [15]. Nowadays, the rates of preoperative diagnosis have been greatly improved thanks to CT and MRI [16]. In fact, the positive diagnosis of adult intussusception can be made entirely on CT with sensitivity close to 100\% [16]. CT allows not only positive diagnosis, but also etiological diagnosis [16]. Laparoscopy was not available in our context. Although not a diagnostic test, laparoscopy allows, in case of suspicion of intussusception, to specify its exact location, the presence or absence of intestinal necrosis. This makes it possible to better pose the therapeutic indications [17].

We performed surgery in all the patients of our series. The treatment of adult intussusception is most often surgical, unlike that in children where non-operative treatment is important [14] [16]. The problem with surgery is the need to distinguish benign underlying pathologies from malignant diseases. These require more extensive resection [14]. In the absence of an extemporaneous examination of the operative specimen, we opted to immediately perform major resections such as hemicolectomy. This option has no doubt contributed to extending the hospital stay of our patients (11.7 days). We did not register any deaths. Mortality in adult intussusception is variable. It is approximately $8 \%$ in case of benign lesion and 50\% in case of underlying malignant lesion [18]. Mortality in our context is probably underestimated because of our short follow-up period. Our study was retrospective and the number of patients was small. A prospective study with a larger number of patients would provide more accurate data.

\section{Conclusion}

Adult intussusception is rare in Burkina tropical environment. The symptomatology is not very specific, without typical acute intestinal obstruction. The etiologies are dominated by inflammatory pathologies and intestinal cancers. The availability of computed tomography and laparoscopy in emergency, as well as the extemporaneous examination of surgical specimens, would considerably improve the prognosis.

\section{References}

[1] Pavlidis, T.E., Atmatzidis, K.S., Galatianos, I., Aslanidou, I., Mirelis, C., Kontos, C. and Papaziogas, T.B. (2004) Intestinal Intussusception in Adults-Our Experience and Review of the Literature. Annals of Gastroenterology, 17, 75-78.

[2] Rathore, M.A., Andrabi, S.I. and Mansha, M. (2006) Adult Intussusception; A Surgical Dilemma. Journal of Ayub Medical College, Abbottabad, 18, 3-6.

[3] Tan, K.Y., Tan, S.M., Tan, A.G., Chen, C.Y., Chng, H.C. and Hoe, M.N. (2003) Adult Intussusception: Experience in Singapore. ANZ Journal of Surgery, 73, 1044-1047. https://doi.org/10.1046/j.1445-2197.2003.t01-22-.x 
[4] Zubaidi, A., Al-Saif, F. and Silverman, R. (2006) Adult Intussusception: A Retrospective Review. Diseases of the Colon and Rectum, 49, 1546-1551. https://doi.org/10.1007/s10350-006-0664-5

[5] Wang, L.T., Wu, C.C., Yu, J.C., Hsiao, C.W., Hsu, C.C. and Jao, S.W. (2007) Clinical Entity and Treatment Strategies for Adult Intussusceptions: 20 Years' Experience. Diseases of the Colon and Rectum, 50, 1941-1949. https://doi.org/10.1007/s10350-007-9048-8

[6] Ghaderi, H., Jafarian, A., Aminian, A. and Daryasari, S. (2010) Clinical Presentation, Diagnosis and Treatment of Adult Intussusceptions, a 20 Years Survey. International Journal of Surgery, 8, 318-320.

https://doi.org/10.1016/j.ijsu.2010.02.013

[7] Guillén-Paredes, M.P., Campillo-Soto, A., Martín-Lorenzo, J.G., Torralba-Martínez, J.A., Mengual-Ballester, M., Cases-Baldó, M.J. and Aguayo-Albasini, J.L. (2010) Adult Intussusception-14 Case Reports and Their Outcomes. Revista Espanola De Enfermedades Digestivas, 102, 32-40. https://doi.org/10.4321/S1130-01082010000100005

[8] Mas, E. and Breton, A. (2007) Pathologies digestives, infections intestinales et invaginations intestinales aigues. Archives de pédiatrie, 14, 159-164.

https://doi.org/10.1016/S0929-693X(07)80021-2

[9] Toso, C. (2005) Intussusception as a Cause of Bowel Obstruction in Adults. Swiss Medical Weekly, 135, 87-90.

[10] Akbulut, S. (2012) Intussusception Due to Inflammatory Fibroid Polyp: A Case Report and Comprehensive Literature Review. World Journal of Gastroenterology, 18, 5745-5752. https://doi.org/10.3748/wjg.v18.i40.5745

[11] Rabbani, K., Narjis, Y., Jgounni, R., Semlani, Z., Difaa, A., Benelkhaiat, R., Louzi, A. and Finech, B. (2012) Adult Intussusception Caused by an Inflammatory Fibroid Ileal Polyp. Acta Chirurgica Belgica, 112, 157-159. https://doi.org/10.1080/00015458.2012.11680815

[12] Zager, J.S., Shaw, J.P., Kaufman, J.P. and DeNoto, G. (2001) Three Cases of Small Bowel Intussusception in Relation to a Rare Lesion: Inflammatory Fibrous Polyps. Digestive Surgery, 18, 142-146. https://doi.org/10.1159/000050116

[13] Balci, N.C., Radjazi, S. and Polat, H. (2000) Adult Intussusception Secondary to Inflammatory Fibroid Polyp: Demonstration by MRI. European Radiology, 10, 1708-1710. https://doi.org/10.1007/s003300000508

[14] Paskauskas, S., Latkauskas, T., Valeikaite, G., Parseliūnas, A., Svagzdys, S., Saladzinskas, Z., Tamelis, A. and Pavalkis, D. (2010) Colonic Intussusception Caused by Colonic Lipoma: A Case Report. Medicina (Kaunas), 46, 477-481.

[15] Fatih, C. (2015) Diagnosis and Treatment of Intestinal Intussusception in Adults: A Rare Experience for Surgeons. International Journal of Clinical and Experimental Medicine, 8, 10001-10005.

[16] Huang, B.Y. and Warshauer, D.M. (2003) Adult Intussusception: Diagnosis and Clinical Relevance. Radiologic Clinics of North America, 41, 1137-1151. https://doi.org/10.1016/S0033-8389(03)00116-7

[17] Barussaud, M., Regenet, N., Briennon, X., de Kerviler, B., Pessaux, P., Kohneh-Sharhi, N., Lehur, P.A., Hamy, A., Leborgne, J., le Neel, J.C. and Mirallie, E. (2006) Clinical Spectrum and Surgical Approach of Adult Intussusceptions: A Multicentric Study. International Journal of Colorectal Disease, 21, 834-839. https://doi.org/10.1007/s00384-005-0789-3 
[18] Parashar, U.D., Holman, R.C., Cummings, K.C., Staggs, N.W., Curns, A.T., Zimmerman, C.M., Kaufman, S.F., Lewis, J.E., Vugia, D.J., Powell, K.E. and Glass, R.I. (2000) Trends in Intussusception-Associated Hospitalizations and Deaths among US Infants. Pediatrics, 106, 1413-1421.

https://doi.org/10.1542/peds.106.6.1413 